\title{
Signs and symptoms of temporomandibular disorders in adolescents
}

\section{Sinais e sintomas de disfunção temporomandibular em adolescentes}

\author{
Leonardo Rigoldi Bonjardim* \\ Maria Beatriz Duarte Gavião** \\ Luciano José Pereira* \\ Paula Midori Castelo* \\ Renata Cunha Matheus Rodrigues Garcia***
}

\begin{abstract}
The aim of this study was to verify the prevalence of signs and symptoms of temporomandibular disorders (TMD) in adolescents and its relationship to gender. The sample comprised 217 subjects, aged 12 to 18 . The subjective symptoms and clinical signs of TMD were evaluated, using, respectively, a self-report questionnaire and the Craniomandibular Index, which has 2 subscales; the Dysfunction Index and the Palpation Index. The results of muscle tenderness showed great variability (0.9-32.25\%). In relation to the temporomandibular joint, tenderness of the superior, dorsal and lateral condyle regions occurred in $10.6 \%, 10.6 \%$ and $7.83 \%$, respectively, of the sample. Joint sound during opening was present in $19.8 \%$ of the sample and during closing in $14.7 \%$. The most prevalent symptoms were joint sounds $(26.72 \%)$ and headache $(21.65 \%)$. There was no statistical difference between genders $(\mathrm{p}>0.05)$, except for the tenderness of the lateral pterygoid muscles, which presented more prevalence in girls. In conclusion, clinical signs and symptoms of TMD can occur in adolescents; however, gender influence was not perceived.
\end{abstract}

DESCRIPTORS: Temporomandibular joint disorders; Teen health.

RESUMO: O objetivo deste estudo foi verificar a prevalência de sinais e sintomas de disfunção temporomandibular (DTM) em adolescentes e sua relação com o gênero. A amostra foi constituída de 217 voluntários, com idade entre 12 e 18 anos. Os sintomas subjetivos e os sinais clínicos de DTM foram avaliados usando-se, respectivamente, um questionário e o "Craniomandibular Index", o qual possui 2 subescalas: "Dysfunction Index" e "Palpation Index". Os resultados para sensibilidade muscular mostraram grande variabilidade (0,9-32,25\%). Com relação à articulação temporomandibular, a sensibilidade à palpação nas regiões superior, dorsal e lateral do côndilo ocorreu, respectivamente, em 10,6\%, 10,6\% e 7,83\% da amostra. A prevalência do ruído articular no movimento de abertura foi de $19,8 \%$ e no fechamento, $14,7 \%$. Os sintomas relatados mais prevalentes foram o ruído articular $(26,72 \%)$ e dor de cabeça $(21,65 \%)$. Nenhuma diferença estatística foi encontrada para a associação entre os gêneros ( $\mathrm{p}>0,05)$, exceto para a sensibilidade no músculo pterigóideo lateral, a qual se apresentou mais prevalente nas meninas. Os sinais clínicos e sintomas subjetivos de DTM foram observados em adolescentes, no entanto a influência do gênero não foi percebida nessa faixa etária.

DESCRITORES: Transtornos da articulação temporomandibular; Saúde do adolescente.

\section{INTRODUCTION}

Temporomandibular disorder (TMD) is a generic term for a number of clinical signs and symptoms involving the masticatory muscles, the temporomandibular joint (TMJ) and associated structures $^{25}$.

Signs and symptoms of TMD in children and adolescents have been studied since the beginning of the $1970 \mathrm{~s}^{11}$. The most prevalent clinical signs of TMD are TMJ sounds (upon palpation), limitation of mandibular movements, TMJ and muscle tenderness ${ }^{23}$. With regard to subjective symptoms, headache, TMJ sounds, bruxism, difficulty in opening the mouth, jaw pain, and facial pain are found ${ }^{22}$.

The etiology of TMD has been considered to be one of the most controversial issues in clinical dentistry. Currently, TMD is considered not a single entity, but a group of several diseases of varying

\footnotetext{
*Graduate Students, Department of Oral Physiology; **Professor, Department of Pediatric Dentistry; ***Professor, Department of Prosthesis and Periodontology - School of Dentistry of Piracicaba, State University of Campinas.
} 
Bonjardim LR, Gavião MBD, Pereira LJ, Castelo PM, Garcia RCMR. Signs and symptoms of temporomandibular disorders in adolescents. Braz Oral Res 2005;19(2):93-8.

etiology and pathology, and controversy still exists because of the limited knowledge regarding its etiology and natural history ${ }^{4}$.

The role of gender in TMD is also extensively discussed in literature, suggesting that TMD is considered to be 1.5-2 times more prevalent in women than in men, and that $80 \%$ of the patients treated for this disorder are women ${ }^{14}$. However, the most prominent gender differences have been found in women aged 20-40 years, and the lowest among children, adolescents and the elderly ${ }^{15}$. Furthermore, the predominance of women is even higher in surveys of people seeking treatment for TMD pain, with a ratio of $4: 1$ or $5: 1^{4}$.

The purpose of this study was to estimate the prevalence of clinical signs and subjective symptoms of TMD in adolescents and its relationship to gender.

\section{MATERIAL AND METHODS}

Adolescents aged between 12 and 18 years were selected from public schools in Piracicaba, Brazil. Firstly, the parents / guardians and the adolescents were informed about the purpose of this research. Adolescents who had received any type of orthodontic treatment before or during the study or were suffering from systemic health disease could not participate in the research. Secondly, a total of 600 written informed consents were distributed. After that, parental and adolescent consent was obtained from 217 subjects (120 girls, mean age of $13.18 \pm 1.28$ years; 97 boys, mean age of $13.28 \pm 1.6$ years), and they were examined. Prior to the examination for clinical signs and symptoms of TMD, an anamnestic questionnaire was filled out, including questions about their general state of health, illness, diseases and oral hygiene. The Research Ethics Committee of the School of Dentistry of Piracicaba approved this research.

\section{Subjective symptom interview}

A self-report questionnaire was used to assess the symptoms ${ }^{22}$ regarding pain in the jaws when functioning (e.g. chewing), unusually frequent headaches (more than once a week and of unknown etiology), stiffness/tiredness in the jaws, difficulty in opening the mouth wide, grinding teeth, and sounds at the TMJ. Each question could be answered with yes or no.

\section{Clinical sign examination}

The signs of TMD were assessed according to the CranioMandibular Index (CMI), as described by Fricton, Schiffman ${ }^{8}$ (1986), by two calibrated examiners $(\mathrm{Kappa}=0.936)$. The CMI produces 3 scores: an overall CMI score, a dysfunction index (DI) score, and a palpation or muscle index (PI) score. The CMI score is an average of the DI and PI scores. All 3 indexes are scaled from 0 to 1 . The CMI measures tenderness and dysfunction in the stomatognathic system and includes all currently recognized signs of TMJ disorders ${ }^{8,9}$. The DI is designed to measure limitation of mandibular movement, pain and deviation of movement, TMJ noise and tenderness. The PI measures the prevalence of muscle tenderness in the stomatognathic system. Thus, this index separates joint problems from muscle problems.

\section{Statistical analysis}

The data were computerized and the SAS package (SAS Institute Cary, North Carolina, USA) was used for their analysis. The prevalence of clinical signs and subjective symptoms was calculated by percentage. The mean values obtained in CMI, PI, DI were compared for subjects with and without each symptom using Mann-Whitney test for the total sample. Data association between each symptom/clinical sign and gender was done using Fisher's Exact Test. For all comparisons, $\mathrm{p}<0.05$ was considered to be statistically significant.

\section{RESULTS}

Tables 1 and 2 show the prevalence of the different clinical signs of TMD (components of CMI) according to gender. Pterygoid lateral muscle tenderness was the most frequent sign of palpation index found in $32.25 \%$ of the total sample. The most frequent sign of DI was TMJ sounds (mouth opening), occurring in $19.8 \%$ of the total sample.

The prevalence of subjective symptoms of TMD according to gender is presented in Table 3. The most prevalent symptom was TMJ sound $(26.72 \%)$, followed by headache (21.65\%). There was no statistical association between genders for clinical signs and symptoms, except for pterygoid lateral muscle tenderness, which presented a higher prevalence among girls $(\mathrm{p}<0.05)$.

Mean values for CMI, DI and PI among adolescents with and without each subjective symptom are presented in Table 4 . Note that for subjects who reported facial/jaw pain, difficulty in open- 
Bonjardim LR, Gavião MBD, Pereira LJ, Castelo PM, Garcia RCMR. Signs and symptoms of temporomandibular disorders in adolescents. Braz Oral Res 2005;19(2):93-8.

TABLE 1 - Percentage distribution of clinical signs (muscle tenderness) according to gender.

\begin{tabular}{|c|c|c|c|}
\hline Muscle tenderness & Female $(\%) \mathrm{n}=120$ & Male $(\%) n=97$ & Total $(\%) n=217$ \\
\hline Anterior temporalis & 6.70 & 3.10 & 5.07 \\
\hline Middle temporalis & 1.70 & 0.00 & 0.90 \\
\hline Posterior temporalis & 1.70 & 1.03 & 1.38 \\
\hline Temporalis insertion & 24.17 & 16.50 & 20.70 \\
\hline Deep masseter & 9.17 & 3.10 & 6.50 \\
\hline Masseter origin & 6.70 & 4.10 & 5.50 \\
\hline Masseter body & 5.80 & 9.30 & 7.40 \\
\hline Masseter insertion & 9.17 & 5.16 & 7.40 \\
\hline Posterior digastric & 25.80 & 22.70 & 24.50 \\
\hline Medial pterygoid (extra-oral) & 12.50 & 8.25 & 10.60 \\
\hline Medial pterygoid (intra-oral) & 25.83 & 20.60 & 23.50 \\
\hline Lateral pterygoid & $38.33^{*}$ & 24.75 & 32.25 \\
\hline Superior sternocleidomastoideus & 5.00 & 3.10 & 4.15 \\
\hline Middle sternocleidomastoideus & 2.50 & 3.10 & 2.77 \\
\hline Inferior sternocleidomastoideus & 5.83 & 1.03 & 3.70 \\
\hline Trapezius insertion & 5.83 & 1.03 & 3.70 \\
\hline Trapezius superior & 5.83 & 7.22 & 6.45 \\
\hline Splenius capitis & 5.83 & 8.25 & 6.91 \\
\hline
\end{tabular}

*Statistical difference $(\mathrm{p}<0.05)$.

TABLE 2 - Percentage distribution of clinical signs (TMJ sounds and tenderness) according to gender.

\begin{tabular}{l|c|c|c}
\hline \multicolumn{1}{c|}{ Clinical signs } & Female (\%) $\mathrm{n}=120$ & Male (\%) $\mathrm{n}=97$ & Total (\%) $\mathrm{n}=217$ \\
\hline Opening click & 20.80 & 18.50 & 19.80 \\
\hline Closing click & 16.60 & 12.40 & 14.70 \\
\hline Tenderness in condyle superior region & 14.17 & 6.19 & 10.60 \\
\hline Tenderness in condyle lateral region & 9.17 & 6.19 & 7.83 \\
\hline Tenderness in condyle dorsal region & 13.33 & 7.22 & 10.60 \\
\hline \hline
\end{tabular}

$p>0.05$.

ing the mouth wide, joint sounds and headache, CMI and PI had significantly higher scores than in adolescents that did not report any symptom $(\mathrm{p}<0.05)$, whereas adolescents who reported TMJ sounds presented a significantly higher mean value for DI ( $\mathrm{p}<0.05)$. In addition, individuals who reported teeth grinding presented significantly higher PI scores than those who did not report this symptom $(\mathrm{p}<0.05)$.

\section{DISCUSSION}

This study evaluated the prevalence of signs and symptoms of TMD in adolescents through a questionnaire and physical examination. The de- cision to use a dysfunction index in this study, specifically the CMI, was based on the possibility of objectively measuring the severity of problems in mandibular movements, joint noises, and muscle and joint tenderness, using clearly defined criteria, simple clinical methods and easy scoring. In addition, this index had a good intra- and inter-examiner correlation ${ }^{8,9}$. The symptom questionnaire proved to be a simple and suitable tool easily understood by the volunteers, thus allowing smaller examiner influence on the individuals and their answers. The application of an anamnestic questionnaire for detecting TMD symptoms has the advantage of being easily used by general practitioners or epidemiologists. The CMI scores obtained 
Bonjardim LR, Gavião MBD, Pereira LJ, Castelo PM, Garcia RCMR. Signs and symptoms of temporomandibular disorders in adolescents. Braz Oral Res 2005;19(2):93-8.

TABLE 3 - Percentage of subjective symptoms according to gender.

\begin{tabular}{l|r|r|r|r|r|r}
\hline \hline \multirow{2}{*}{ Symptoms } & \multicolumn{2}{|c|}{ Female } & \multicolumn{2}{c|}{ Male } & \multicolumn{2}{c}{ Total } \\
\cline { 2 - 7 } & $\mathrm{n}$ & $\%$ & $\mathrm{n}$ & $\%$ & $\mathrm{n}$ & $\%$ \\
\hline Facial/jaw pain & 17 & 14.16 & 11 & 11.34 & 28 & 12.90 \\
\hline Difficulty in mouth opening & 5 & 4.16 & 2 & 2.06 & 7 & 3.22 \\
\hline Joint sounds & 27 & 22.50 & 31 & 31.96 & 58 & 26.72 \\
\hline Teeth grinding & 19 & 15.83 & 20 & 20.61 & 39 & 17.98 \\
\hline Headache & 28 & 23.33 & 19 & 19.58 & 47 & 21.65 \\
\hline \hline
\end{tabular}

TABLE 4 - Mean values for CMI, DI and PI among adolescents with and without each subjective symptom.

\begin{tabular}{l|c|c|c|c|c|c}
\hline \hline \multirow{2}{*}{ Symptoms } & \multicolumn{2}{c|}{ CMI } & \multicolumn{2}{c|}{ DI } & \multicolumn{2}{c}{ PI } \\
\cline { 2 - 7 } & $\begin{array}{c}\text { Without } \\
\text { symptom }\end{array}$ & $\begin{array}{c}\text { With } \\
\text { symptom }\end{array}$ & $\begin{array}{c}\text { Without } \\
\text { symptom }\end{array}$ & $\begin{array}{c}\text { With } \\
\text { symptom }\end{array}$ & $\begin{array}{c}\text { Without } \\
\text { symptom }\end{array}$ & $\begin{array}{c}\text { With } \\
\text { symptom }\end{array}$ \\
\hline Facial/jaw pain & $0.075^{\mathrm{a}}$ & $0.155^{\mathrm{b}}$ & 0.087 & 0.120 & $0.055^{\mathrm{a}}$ & $0.190^{\mathrm{b}}$ \\
\hline Difficulty in mouth opening & $0.082^{\mathrm{a}}$ & $0.186^{\mathrm{b}}$ & 0.089 & 0.168 & $0.068^{\mathrm{a}}$ & $0.204^{\mathrm{b}}$ \\
\hline Joint sounds & $0.069^{\mathrm{a}}$ & $0.130^{\mathrm{b}}$ & $0.086^{\mathrm{a}}$ & $0.108^{\mathrm{b}}$ & $0.050^{\mathrm{a}}$ & $0.133^{\mathrm{b}}$ \\
\hline Teeth grinding & 0.082 & 0.098 & 0.091 & 0.096 & $0.067^{\mathrm{a}}$ & $0.100^{\mathrm{b}}$ \\
\hline Headache & $0.078^{\mathrm{a}}$ & $0.111^{\mathrm{b}}$ & 0.090 & 0.096 & $0.059^{\mathrm{a}}$ & $0.123^{\mathrm{b}}$ \\
\hline \hline
\end{tabular}

$\mathrm{a} \neq \mathrm{b} ; \mathrm{p}<0.05$. CMI: Craniomandibular Index. DI: Dysfunction index. PI: Palpation index.

in this study were lower than those presented in other studies ${ }^{8,9}$, probably because this sample was comprised by adolescents. Studies have reported that severe disorder at a young age is rare, supporting the results presented ${ }^{25}$. Moreover, the study was carried out in a randomized population and not among people looking for treatment.

The results of muscle tenderness showed that a higher prevalence was observed in the lateral pterygoid muscle (32.25\%), but this result must be carefully considered, due to the low specificity of palpation. Nevertheless, this muscle has been part of many current examination schemes ${ }^{4,25,26}$. It must be considered that the discomfort or pain observed in response to palpation of the "lateral pterygoid area" may be caused by anatomical structures other than the lateral pterygoid muscle ${ }^{24}$. There was also a high prevalence of tenderness in the posterior digastric muscle $(24.5 \%)$, medial pterygoid muscle (intraoral) $(23.5 \%)$ and temporalis insertion $(20.7 \%)$. The scores for intra-oral muscle palpation indicated that the frequency of tenderness of these muscles was higher than at other sites, except for the posterior digastric muscle. Intra-oral palpation may cause pain in normal subjects and thus, false-positives that may lead to a wrong diagnosis, such as myofascial pain ${ }^{8}$.

As reported in the related literature, the anterior temporalis region and masseter muscles have been extensively evaluated. In this research, tenderness of the anterior temporalis region was observed in $5.07 \%$ of the adolescents, while for the masseter muscle the correspondent value was $7.4 \%$. These results are similar to those of other studies in adolescents ${ }^{17}$ and young adults ${ }^{18}$. Masseter and anterior temporalis area palpation can be considered to be reliable and valuable. This fact supports the belief that pressure pain sensation in these muscles is not derived predominantly from the cutaneous tissues, but from the muscle itself $^{10}$.

Neck muscle tenderness was also evaluated as part of clinical signs exam in CMI (Table 1). Despite the low prevalence of tenderness in these muscles, their evaluation in TMD patients is important. Moreover, the findings obtained support the theory that a complementary examination of this area should be performed, even when TMD patients do not report any neck problems. Fink et al. ${ }^{7}$ (2002), corroborating the findings of this study, mentioned that patients with TMD frequently show symptoms related to the cervical spine region.

Tenderness of the superior and dorsal condyle region occurred in $10.6 \%$ of the sample, whereas for the lateral region, it occurred in $7.83 \%$. A number of studies have found a prevalence of TMJ tenderness in adolescents varying from $7.1 \%$ to $22.5 \%^{2,17,22}$. Moreover, differences in palpation 
Bonjardim LR, Gavião MBD, Pereira LJ, Castelo PM, Garcia RCMR. Signs and symptoms of temporomandibular disorders in adolescents. Braz Oral Res 2005;19(2):93-8.

techniques and pressure make comparisons very unreliable. In addition, in the present research, TMJ palpation was conducted in three different sites, which could be the cause of disagreement among these results.

The percentage of joint sound upon palpation during mouth opening and closing was 19.8\% and $14.7 \%$, respectively, lower than that observed in the study of Nassif et al. ${ }^{18}$ (2003) $(24.7 \%$ and $19.5 \%)$, performed in young adults. Farsi ${ }^{6}$ (2003) found a prevalence of $11.8 \%$ for joint sounds in children aged 3 to 15 . The small differences among these studies could be due to the fact that the incidence of signs and symptoms generally increase and also fluctuate with age ${ }^{5}$.

The most prevalent subjective symptoms present were TMJ sounds $(26.72 \%)$, headache $(21.65 \%)$, tooth grinding $(17.98 \%)$, and pain in the face or jaw regions (12.9\%). Conti et al. ${ }^{2}$ (2003) also found TMJ sounds followed by headache as the most commonly reported symptoms, although with lower values. Melis, Abou-Atme ${ }^{16}$ (2003) and Conti et al. ${ }^{2}$ (2003) observed a prevalence rate of $27.2 \%$ and $20.5 \%$, respectively, for tooth grinding. Nevertheless, the prevalence of tooth grinding is difficult to estimate, since quite often the subjects are unaware of having the disorder, which can under- or overestimate the amount of people affected $^{1}$. The diversity of TMD prevalence among different studies has been attributed to the differences in the age groups, the sample sizes and their composition, the number of examiners, as well as the diagnostic criteria used ${ }^{6}$.

Our findings showed no statistical difference in prevalence of signs and symptoms of TMD between boys and girls. The lateral pterygoid muscle tenderness showed greater prevalence among females, but as mentioned above, the findings for this muscle can be overestimated. Moreover, one problem much found in the literature on TMD is the sparse number of men in comparison with women who seek treatment, resulting in studies that have small numbers of men or studies that limit their investigations to women ${ }^{21}$. In this research, the lack of statistical differences between genders could be explained by the fact that the sample was comprised of adolescents, some of whom probably have not yet been affected by the effects of puberty. About $90 \%$ of the sample was aged 12 to 14 ( \pm 1.43 years). Signs and symptoms of TMD onset tend to occur more frequently in women after puberty and peaks in the reproductive years, and they are smaller in number among children and adolescents, and among the elderly ${ }^{15}$.
When CMI, PI and DI values in subjects with or without each subjective symptom were compared, there were significantly higher scores for DI in subjects who reported joint sounds. PI and CMI presented significantly higher scores in individuals with facial/jaw pain, difficulty in opening the mouth wide, joint sounds and headache. Additionally, for PI, the same findings were observed when the analysed symptom was teeth grinding. These results are in accordance with those of Kleinknecht et $a l .{ }^{13}$ (1986) and De Kanter et al. ${ }^{3}$ (1993), who found a correspondence between subjective reports of TMD symptoms and clinical findings. Katz, Heft $^{12}$ (2002) found that $53 \%$ of subjects with positive masticatory muscle tenderness also presented positive TMJ sounds and $25 \%$ of the subjects with TMJ sounds also presented positive masticatory muscle tenderness. Conti et al. ${ }^{2}$ (2003) found an association between joint sounds and joint tenderness upon palpation. This study supports the proposal that clinical signs and symptoms should be evaluated in combination. However, it is important to note that most of the population-based studies on TMD report a discrepancy between the frequency of symptoms and the frequency of signs of TMJ disturbances. In addition, studies have reported varying relationships between subjectively perceived symptoms and signs found upon clinical examination.

Since signs and symptoms of TMD obviously make an early appearance, routine dental examination should include evaluation of these signs and symptoms to identify patients who should be observed more closely. Nevertheless, it must be considered that the signs and symptoms in growing individuals may be due in part to growth changes ${ }^{19}$. In this phase there are both local and central factors associated from time to time with TMD developmentand the prediction of single TMD signs for the development of severe disorder later in life is unclear ${ }^{20}$.

\section{CONCLUSION}

Based on the results above presented, it was concluded that clinical signs and symptoms of TMD were present in adolescents. Muscle tenderness and joint sounds were the most prevalent clinical signs and symptoms, respectively. In relation to gender differences, only lateral pterygoid muscle tenderness showed greater prevalence among girls, but this finding must be interpreted carefully. The presence of clinical signs associated with subjective symptoms was also confirmed. The 
Bonjardim LR, Gavião MBD, Pereira LJ, Castelo PM, Garcia RCMR. Signs and symptoms of temporomandibular disorders in adolescents. Braz Oral Res 2005;19(2):93-8.

index scores were low, indicating mild disorder, but these findings do not detract from the importance of early diagnosis, in order to detect factors that can interfere with proper stomatognathic system growth and development.

\section{REFERENCES}

1. Bader G, Lavigne G. Sleep bruxism; an overview of an oromandibular sleep movement disorder. Sleep Med Rev 2000;4:27-43.

2. Conti A, Freitas M, Conti P, Henriques J, Janson G. Relationship between signs and symptoms of temporomandibular disorders and orthodontic treatment: a cross-sectional study. Angle Orthod 2003;73:411-7.

3. De Kanter RJ, Truin GJ, Burgersdijk RC, Van't Hof MA, Battistuzzi PG, Kalsbeek H, et al. Prevalence in the Dutch adult population and a meta-analysis of signs and symptoms of temporomandibular disorder. J Dent Res 1993;72:1509-18.

4. Dworkin SF, LeResche L. Research diagnostic criteria for temporomandibular disorders: review, criteria, examinations and specifications, critique. J Craniomandib Disord 1992;6:301-55.

5. Egermark-Eriksson I, Carlsson GE, Magnusson T. A 20year longitudinal study of subjective symptoms of temporomandibular disorders from childhood to adulthood. Acta Odontol Scand 2001;59:40-8.

6. Farsi NM. Symptoms and signs of temporomandibular disorders and oral parafunctions among Saudi children. J Oral Rehabil 2003;30:1200-8.

7. Fink M, Tschernitschek H, Stiesch-Scholz M. Asymptomatic cervical spine dysfunction (CSD) in patients with internal derangement of the temporomandibular joint. Cranio 2002;20:192-7.

8. Fricton JR, Schiffman EL. Reliability of a craniomandibular index. J Dent Res 1986;65:1359-64.

9. Fricton JR, Schiffman EL. The craniomandibular index: validity. J Prosthet Dent 1987;58:222-8.

10. Fujisawa M, Shoji S, Ishibashi K, Clark GT. Pressure pain threshold with and without iontophoretic anesthesia of the masseter muscle in asymptomatic males. J Orofac Pain 1999;13:97-103.

11. Grosfeld O, Czarnecka B. Musculo-articular disorders of the stomatognathic system in school children examined according to clinical criteria. J Oral Rehabil 1977;4:193-200.

12. Katz J, Heft M. The epidemiology of self-reported TMJ sounds and pain in young adults in Israel. J Public Health Dent 2002;62:177-9.

13. Kleinknecht RA, Mahoney ER, Alexander LD, Dworkin $\mathrm{SF}$. Correspondence between subjective report of temporomandibular disorder symptoms and clinical findings. J Am Dent Assoc 1986;113:257-61.

\section{ACKNOWLEDGEMENTS}

L.R.B. was a CAPES scholarship holder. The authors thank Prof. Glaucia Maria Bovi Ambrosano for the statistical analysis.

14. LeResche L. Epidemiology of temporomandibular disorders: implications for the investigation of etiologic factors. Crit Rev Oral Biol Med 1997;8:291-305.

15. Meisler JG. Chronic pain conditions in women. J Womens Health 1999;8:313-20.

16. Melis M, Abou-Atme YS. Prevalence of bruxism awareness in a Sardinian population. Cranio 2003;21:144-51.

17. Mohlin B, Pilley JR, Shaw WC. A survey of craniomandibular disorders in 1,000 12-year-olds. Study design and baseline data in a follow-up study. Eur J Orthod 1991;13:111-23.

18. Nassif NJ, Al-Salleeh F, Al-Admawi M. The prevalence and treatment needs of symptoms and signs of temporomandibular disorders among young adult males. J Oral Rehabil 2003;30:944-50.

19. Pahkala RH, Laine-Alava MT. Changes in TMD signs and in mandibular movements from 10 to 15 years of age in relation to articulatory speech disorders. Acta Odontol Scand 2000;58:272-8.

20. Pahkala R, Qvarnstrom M. Can temporomandibular dysfunction signs be predicted by early morphological or functional variables? Eur J Orthod 2004;26:367-73.

21. Phillips JM, Gatchel RJ, Wesley AL, Ellis E $3^{\text {rd }}$. Clinical implications of sex in acute temporomandibular disorders. J Am Dent Assoc 2001;132:49-57.

22. Riolo ML, Brandt D, TenHave TR. Associations between occlusal characteristics and signs and symptoms of TMJ dysfunction in children and young adults. Am J Orthod Dentofacial Orthop 1987;92:467-77.

23. Sonmez H, Sari S, Oksak Oray G, Camdeviren H. Prevalence of temporomandibular dysfunction in Turkish children with mixed and permanent dentition. J Oral Rehabil 2001;28:280-5.

24. Stratmann U, Mokrys K, Meyer U, Kleinheinz J, Joos U, Dirksen D, et al. Clinical anatomy and palpability of the inferior lateral pterygoid muscle. J Prosthet Dent 2000;83:548-54.

25. Thilander B, Rubio G, Pena L, de Mayorga C. Prevalence of temporomandibular dysfunction and its association with malocclusion in children and adolescents: an epidemiologic study related to specified stages of dental development. Angle Orthod 2002;72:146-54.

26. Wright EF. Referred craniofacial pain patterns in patients with temporomandibular disorder. J Am Dent Assoc 2000;131:1307-15. 